\title{
RETRACTED ARTICLE: A variety of pesticides trigger in vitro $\alpha$-synuclein accumulation, a key event in Parkinson's disease
}

\author{
Areski Chorfa $^{1} \cdot$ Corinne Lazizzera $^{1} \cdot$ Dominique Bétemps $^{1} \cdot$ Eric $^{\text {Morignat }}{ }^{1}$. \\ Sébastien Dussurgey ${ }^{2} \cdot$ Thibault Andrieu $^{2} \cdot$ Thierry Baron $^{1}$
}

Received: 2 June 2014 / Accepted: 8 October 2014 / Published online: 19 October 2014

(C) Springer-Verlag Berlin Heidelberg 2014

This article has been retracted at the request of the authors and by agreement of the editor. Re-analyses of the raw data did not confirm the published data and they did not support the major conclusions of this publication. The authors apologize to the readers of Archives of Toxicology for any inconvenience caused by this retraction.

The online version of this article contains the full text of the retracted article as electronic supplementary material.

Electronic supplementary material The online version of this article (doi:10.1007/s00204-014-1388-2) contains supplementary material, which is available to authorized users.

Thierry Baron

thierry.baron@anses.fr

1 Neurodegenerative Diseases Unit, Agence nationale de sécurité sanitaire de l'alimentation, de l'environnement et du travail (ANSES), 31 Avenue Tony Garnier, 69394 Lyon Cedex 07, France

2 INSERM SFR Biosciences Gerland, US8/UMS3444, Tour INSERM CERVI, 21 Avenue Tony Garnier, 69365 Lyon Cedex 07, France 